\title{
Ghana's National Health Insurance Scheme: An Ordinal Probit Valuation of Willingness to Pay Higher Premiums for Improved Services
}

\author{
Richard Puurbalanta ${ }^{1,}$, Mark Adjei ${ }^{1}$, Vida Afosaa ${ }^{2}$ \\ ${ }^{1}$ Department of Statistics, Faculty of Mathematical Sciences, University for Development Studies, Navrongo Campus, Tamale, \\ Ghana \\ ${ }^{2}$ Department of Mathematics and Statistics, Faculty of Applied Sciences, Sunyani Technical University, Sunyani, Ghana
}

Email address:

rpuurbalanta@uds.edu.gh (R. Puurbalanta)

${ }^{*}$ Corresponding author

To cite this article:

Richard Puurbalanta, Mark Adjei, Vida Afosaa. Ghana's National Health Insurance Scheme: An Ordinal Probit Valuation of Willingness to Pay Higher Premiums for Improved Services. American Journal of Theoretical and Applied Statistics. Vol. 9, No. 3, 2020 , pp. 57-62. doi: 10.11648/j.ajtas.20200903.15

Received: November 18, 2019; Accepted: April 17, 2020; Published: May 27, 2020

\begin{abstract}
The importance of improved healthcare services under Ghana's National Health Insurance Scheme (NHIS) is nationwide admitted. However, service improvement for insurance schemes comes with extra cost. To fill the funding gap, insurance schemes typically charge enhanced premiums. This requires clients' approval and cooperation to implement. For this reason, this study was conducted to assess Ghana's NHIS subscribers' willingness to pay (WTP) enhanced premiums for improved services. Some socio-economic and demographic factors were used as covariates. WTP, being the dependent variable, was categorized into high WTP, moderate WTP, low WTP, and no WTP enhanced premiums. The likelihood of a client falling in a particular WTP category was examined using the Cumulative Ordinal Probit (COP) regression model. A likelihood ratio chi-square of 58.82 with $p<0.000$ shows that the model was statistically significant, and fit for prediction. Results showed that age-groups 18-30, 30-45, unemployed, tertiary education, and level of income significantly influenced WTP. Predictions showed that for any average national health insurance user, the probability of being in high WTP, moderate WTP, low WTP and no WTP premium are respectively $0.51,0.27,0.11$ and 0.12 . Based on the results of this study, we recommend that Ghana's NHIS should institute a progressive premium regime in order to cater for the different needs and financial abilities of clients, thus helping to fill the funding gap.
\end{abstract}

Keywords: WTP, Premiums, MLE, Cumulative Ordinal Probit Regression Model, NHIS

\section{Introduction}

Ghana has experienced considerable evolution in its healthcare financing. Immediately after independence, direct out-of-pocket consumption of healthcare in public health facilities was abolished [1]. Financing of health in the public sector was entirely dependent on tax revenues [1]. However, the sustainability of this form of healthcare financing became uncertain as Ghana's economy began to experience considerable downturn, especially in the early 1980s [2]. This necessitated the "cash and carry" system. Its implementation compounded the utilization problem by creating financing barrier to healthcare access especially for the poor.
Consequently more deaths were recorded [3]. This necissitated the introduction of health insurance. In 2003, the National Health Insurance Scheme (NHIS) was passed into law in Ghana.

Though NHIS continues to play a critical role towards attaining universal health coverage in Ghana, the ability of NHIS to continue its operations is threatened financially [3]. Additionally, poor quality healthcare in NHIS accredited health facilities has reduced clients' trust in the scheme and consequently decreased (re) enrolment rates.

At the same time, the importance of improved services in NHIS is nationwide acknowledged. Increasingly, clients are demanding more services, by type, quantity and quality. This 
contrasts sharply with low premiums charged by the NHIS. The resulting pressure between the demand for more and better services, on the one hand, and low premiums, on the other, has created a funding gap. The successful implementation of improved NHIS requires clients' approval and cooperation since it comes with high cost.

A study to assess clients' ability and willingness to pay (WTP) higher premiums under the NHIS is therefore paramount. There is the need to examine the NHIS clients' benefits perceptions and identify the socio-economic and demographic factors that influence clients' WTP higher premiums.

Most empirical studies on the WTP for improved health insurance indicate that socio-economic and demographic characteristics such as income, household size, education, age, distance from existing service facilities, employment status and sex influence WYP higher premiums for improved health insurance services. For instance, [4] estimated WTP Community Based Health Insurance (CBHI) among informal sector workers in Urban Bangladesh. They found that about $86.7 \%$ of respondents were willing to pay higher premiums. [5] investigated the effect of social capital on household WTP for CBHI schemes in rural Tanzania. They used biding game $[6,7]$ to elicit information about households' WTP. Their results showed that social capital variables such as membership in social organization and network, trust among community members, trust on scheme management, and income level are positively and significantly related to WTP.

This study seeks to formulate an ordered regression model to investigate NHIS clients' ability and WTP higher premiums for improved services. WTP, being the dependent variable, was categorized into high WTP, moderate WTP, low WTP, and no WTP premiums. The likelihood of a client falling in a particular WTP category was estimated using the cumulative ordinal probit (COP) model [8]. The primary objective was to predict the probability of falling in a particular WTP category given some predictor characteristics of clients in the study area.

\section{Methodology}

The target population for this research included all NHIS subscribers in the Upper East Region of Ghana. A sample size of 335 was used in order to capture a representative view of the entire population using systematic sampling technique at the various NHIS offices across the region. A contingent valuation design was used to collect responses in this study [8]. A contingent valuation method is utility based, and people are asked how much money they would be willing to pay to maintain or improve services or activities. The method is a survey-based hypothetical and direct method to elicit monetary value for improvement in goods or services [9].

Covariates included clients' socio-economic and demographic characteristics such as age, sex, marital status, occupation, religious status, income level, health condition and educational background.

WTP questions were asked in two stages. Clients were first asked whether they would be willing to pay a percentage increment on the already existing premium for improvements in NHIS services. They were subsequently questioned about the maximum amounts they were WTP for improved services. The responses were then ranked as High WTP if a respondent answered "yes to $25 \%$ increase in existing premium, and yes to a further increase of $\geq 25 \%$ ", Moderate WTP if the respondent answered "yes to $25 \%$ increase in premium, but no to any further increases", Low WTP if the respondent answered "no to $25 \%$ increase in premium, but yes to $\leq 25 \%$ decreases in existing premium", No WTP if a respondent answered "no to any form of premium increases".

Five quality attributes were assessed using a contingent valuation set-up during the WTP elicitation. These included inclusion of all drugs in Ghana's NHIS drug list, Development of an electronic application for online renewal of membership such that premiums are paid via electronicpayment, Replace broken equipment and dilapidated infrastructure in all NHIS accredited facilities, Improve antenatal care to reduce the risk of maternal mortality, and also ensure efficient monitoring and supervision in both insurance and healthcare providers' centers.

\subsection{The Ordered Probit Model}

Let

$$
y_{i}^{*}=x_{i}^{T} \beta+\varepsilon_{i}
$$

be a latent Gaussian regression model, where $x_{i}$ are covariates, $\beta$ a vector of unknown coefficients, $\varepsilon_{i} \sim N(0,1)$.

The values of $y_{i}^{*}$ in (1) cannot be directly observed, but are translated into multiple binary ordered outcomes using $\alpha_{j}$ as the cut-points of the ranking $[8,10]$. That is:

$$
\mathrm{y}_{i}=\left\{\begin{array}{c}
j, \alpha_{j-1}<y_{i}^{*} \leq \alpha_{j} \\
0, \text { otherwise }
\end{array}\right.
$$

where $\alpha_{j} \in \mathbb{R}$, such that $\alpha_{1}<\alpha_{2} \ldots<\alpha_{J}$.

The objective is to predict the probability of a response falling in the $j^{\text {th }}$ cut-point given some covariates. This is given by

$$
\begin{gathered}
p\left(y_{i} \leq j \mid x_{i}\right)=p\left(\alpha_{j-1}<y_{i}^{*} \leq \alpha_{j}\right) \\
=p\left(\alpha_{j-1}-x_{i}^{T} \beta<\varepsilon_{i} \leq \alpha_{j}-X_{i}^{T} \beta\right) \\
=\Phi\left(\alpha_{j}-x_{i}^{T} \beta\right)-\Phi\left(\alpha_{j-1}-x_{i}^{T} \beta\right) \\
=\Phi^{-1}\left(\alpha_{j}-X \beta\right)
\end{gathered}
$$

where $\Phi($.$) denotes the CDF of the standard normal density$ $F\left(\varepsilon_{i}\right)=\left(\frac{1}{2 \pi}\right)^{-\frac{n}{2}} \exp \left(-\frac{1}{2} \varepsilon_{i}^{2}\right)$ and $\Phi^{-1}($.$) , the inverse of the$ $\mathrm{CDF}$ for $\varepsilon$, is the probit link for cumulative probabilities that transforms $\Phi\left(\alpha_{j}-X \beta\right)$ to a GLM.

Hence, the likelihood function, which is the product of the probabilities associated with each discrete outcome [11], is given by: 


$$
L\left(\beta, \alpha \mid y_{i}\right)=\prod_{i=1}^{n} \prod_{j=1}^{J} p\left(y_{i} \leq j \mid \beta, \alpha\right)=\prod_{i=1}^{n} \prod_{j=1}^{J} \Phi\left(\alpha_{j}-x_{i}^{T} \beta\right)-\Phi\left(\alpha_{j-1}-x_{i}^{T} \beta\right)
$$

\subsection{Maximum Likelihood Estimation of Parameters}

We proceed by first defining an indicator matrix $I\left(y_{i}=j\right)$. Thus,

$$
L(\beta, \alpha \mid y)=\prod_{i=1}^{n} \sum_{j=1}^{J}\left[\Phi\left(\alpha_{j}-X \beta\right)-\Phi\left(\alpha_{j-1}-X \beta\right)\right]^{I\left(y_{i}=j\right)} .
$$

The log-likelihood is simply

$$
\begin{aligned}
\log L(\beta, \alpha \mid x, y) & =\prod_{i=1}^{n} \sum_{j=1}^{J} I\left(y_{i}=j\right) \log \left[\Phi\left(\alpha_{j}-X \beta\right)-\Phi\left(\alpha_{j-1}-X \beta\right)\right] \\
= & \prod_{i=1}^{n} \sum_{j=1}^{J} I\left(y_{i}=j\right) \log \left[\Phi\left(\alpha_{y_{i}}\right)-\Phi\left(\alpha_{y_{i}-1}\right)\right] \\
= & \prod_{i=1}^{n} \sum_{j=1}^{J} I\left(y_{i}=j\right) \log P_{i j}
\end{aligned}
$$

where $I$ is the identity matrix.

Maximum likelihood estimates are obtained by assuming that the curve of $L(\beta, \alpha \mid x, y)$ is concave [12], and at $\hat{\beta}$ and $\hat{\alpha}$,

$$
\frac{\partial \log L\left(P_{i j}\right)}{\partial\left(\beta, \alpha_{j}\right)}=0, j=1, \ldots, J-1 .
$$

subject to $\alpha_{0}=-\infty, \alpha_{1}=0, \alpha_{j}=\infty$ and $\sigma=1$.

Newton-Raphson's iterative algorithm [13] was used to sample estimated parameters. Likelihood ratio test, approximated by $\chi_{[P+J-2]}^{2}=2\left[\log L_{\text {Model }}-\log L_{\text {No Model }}\right]$, was used to measure validity of the model.

\subsection{Computation of Marginal Effects}

The marginal effect of an increase in $x_{i}$ on the chance of selecting the $j$ th alternative is given by $[14,15]$ :

$$
\frac{\partial\left(P_{i k}\right)}{\partial\left(X_{i k}\right)}=\left[F\left(\alpha_{j-1}-x_{i}^{T} \beta\right)-F\left(\alpha_{j}-x_{i}^{T} \beta\right)\right] \beta
$$

The ordered probit model with $j$ alternatives will have $j$ sets of marginal effects. The marginal effects of each factor on the different alternatives sum to zero.

\section{Results and Discussion}

Model validation statistics, coefficients of regression, and marginal effects were all computed using STATA version 14 [17].
As shown in Table 1, the likelihood ratio chi-square of 58.82 with a $p<0.0000$ shows that the model is statistically significant, and fit for prediction. The likelihood ratio chisquare tests that at least one of the predictor's coefficient is not equal to zero in the model. The pseudo $R^{2}$ of 0.0856 is also given in Table 1.

In Table 2, we see the ML estimates, their standard errors, Z-tests and their associated p-values at $95 \%$ confidence intervals. The ML coefficients of the thresholds are also estimated as $\alpha_{1}=-0.1806245, \alpha_{2}=0.3108365$, and $\alpha_{3}=1.166707$.

Results reported in Table 2 shows that age groups 18-30 and 31-45 significantly influenced WTP for improved NHIS service. Furthermore, the estimation results show significant variation in the relationship of the response with unemployed at 5\% significance level. Income levels of $>$ GHC600 have significant impact on WTP, implying that higher levels of

\begin{tabular}{|c|c|c|c|c|c|c|c|}
\hline \multicolumn{8}{|c|}{ Maximum Likelihood Estimates } \\
\hline \multirow[t]{3}{*}{ Predictors } & \multirow[b]{2}{*}{ Below 18 years } & \multirow{2}{*}{$\begin{array}{l}\text { Coefficient } \\
\text { Reference }\end{array}$} & \multirow{2}{*}{$\begin{array}{l}\text { Std Err. } \\
-\end{array}$} & \multirow{2}{*}{$\begin{array}{l}\mathbf{z} \\
-\end{array}$} & \multirow{2}{*}{$\begin{array}{l}\mathbf{P}>|\mathbf{z}| \\
-\end{array}$} & \multicolumn{2}{|c|}{$95 \%$ conf. interval } \\
\hline & & & & & & - & - \\
\hline & 18 years -30 years & 1.3293 & 0.3864 & 3.44 & 0.001 & 0.5721 & 2.0866 \\
\hline \multirow[t]{3}{*}{ Age } & 31 years -45 years & 1.4491 & 0.4399 & 3.29 & 0.001 & 0.5868 & 2.3113 \\
\hline & 46 years -65 years & 0.8898 & 0.4831 & 1.84 & 0.066 & -0.0571 & 1.8367 \\
\hline & Above 65 years & 0.8251 & 0.6114 & 1.35 & 0.177 & -0.3732 & 2.0233 \\
\hline Sex & Female & Reference & - & - & - & & \\
\hline
\end{tabular}
income influence the probability of falling in a particular category of WTP. We can also see from Table 2 that tertiary education has a significant relationship with WTP.

Table 1. Model Fit Information.

\begin{tabular}{llll}
\hline Log likeliood & LR chi-square & P-value & ${\text { Pseudo } \boldsymbol{R}^{\mathbf{2}}}$ \\
\hline-314.27941 & 58.82 & 0.0000 & 0.0856 \\
\hline
\end{tabular}

Table 2. Maximum Likelihood Estimates. 


\begin{tabular}{|c|c|c|c|c|c|c|c|}
\hline \multicolumn{8}{|c|}{ Maximum Likelihood Estimates } \\
\hline \multicolumn{2}{|l|}{ Predictors } & \multirow{2}{*}{$\begin{array}{l}\text { Coefficient } \\
0.1645\end{array}$} & \multirow{2}{*}{$\begin{array}{l}\text { Std Err. } \\
0.1731\end{array}$} & \multirow{2}{*}{$\begin{array}{l}\mathbf{z} \\
0.95\end{array}$} & \multirow{2}{*}{$\begin{array}{l}\mathbf{P}>|\mathbf{z}| \\
0.342\end{array}$} & \multicolumn{2}{|c|}{$95 \%$ conf. interval } \\
\hline \multirow{6}{*}{ Marital status } & Male & & & & & -0.1748 & 0.5038 \\
\hline & Married & Reference & - & - & - & & \\
\hline & Never married & 0.1642 & 0.2389 & 0.69 & 0.492 & -0.3039 & 0.6324 \\
\hline & Divorced & -1.2901 & 0.7979 & -1.62 & 0.106 & -2.8539 & 0.2737 \\
\hline & Widow/widower & -0.0950 & 0.5777 & -0.16 & 0.869 & -1.2273 & 1.0372 \\
\hline & Student & Reference & - & - & - & & \\
\hline \multirow{3}{*}{ Occupation } & Unemployed & -0.7605 & 0.2696 & -2.82 & 0.005 & -1.2889 & -0.2320 \\
\hline & Civil servant & -0.0206 & 0.3661 & -0.06 & 0.955 & -0.7381 & 0.6969 \\
\hline & Self-employed & -0.6039 & 0.3740 & -1.91 & 0.056 & -1.2220 & 0.0142 \\
\hline \multirow{4}{*}{ Religion } & Christian & Reference & - & - & - & & \\
\hline & Islam & 0.2591 & 0.2243 & 1.15 & 0.248 & -0.1806 & 0.6988 \\
\hline & Traditionalist & -0.0353 & 0.3154 & -0.09 & 0.925 & -0.7683 & 0.6977 \\
\hline & Below GHC 100 & Reference & - & - & - & & \\
\hline \multirow{3}{*}{ Income } & GHC 100-GHC 599 & 0.3331 & 0.1904 & 1.75 & 0.080 & -0.0400 & 0.7062 \\
\hline & GHC 600 - GHC 1000 & 0.6838 & 0.2108 & 3.24 & 0.001 & 0.2707 & 1.0969 \\
\hline & Above GHC 1000 & 0.8345 & 0.2898 & 2.88 & 0.004 & 0.2665 & 1.4024 \\
\hline \multirow{4}{*}{ Health condition } & Excellent & Reference & - & - & - & & \\
\hline & Good & 0.2631 & 0.1617 & 1.63 & 0.104 & -0.0538 & 0.5800 \\
\hline & Poor & 0.1613 & 0.2694 & 0.60 & 0.549 & -0.3668 & 0.6894 \\
\hline & None & Reference & - & - & - & & \\
\hline \multirow{4}{*}{ Educational level } & Basic & -0.1752 & 0.2373 & -0.74 & 0.460 & -0.6403 & 0.2900 \\
\hline & Secondary & -0.1959 & 0.2725 & -0.72 & 0.472 & -0.7300 & 0.3382 \\
\hline & Tertiary & -0.8193 & 0.3222 & -2.54 & 0.011 & -1.4507 & -0.1878 \\
\hline & Vocational & 5.1194 & 187.45 & 0.03 & 0.978 & -362.27 & 372.51 \\
\hline \multirow{4}{*}{ WTP } & & & & & & & \\
\hline & $\alpha_{1}$ & -0.1806 & 0.4826 & - & - & -1.1265 & 0.7653 \\
\hline & $\alpha_{2}$ & 0.3108 & 0.4850 & - & - & -0.6397 & 1.2614 \\
\hline & $\alpha_{3}$ & 1.1667 & 0.4904 & - & - & 0.2056 & 2.1278 \\
\hline
\end{tabular}

\subsection{Predicted Probabilities}

Figure 1 shows the predicted probabilities for the four WTP categories evaluated at the sample means of the data. The predictions in Figure 1 show that for any average national health insurance user, the probability of being in high $(W T P=4)$, moderate $(W T P=3)$, low $(W T P=2)$ or no $(W T P=1)$ premium are respectively $0.51,0.27,0.11$ and 0.12 .

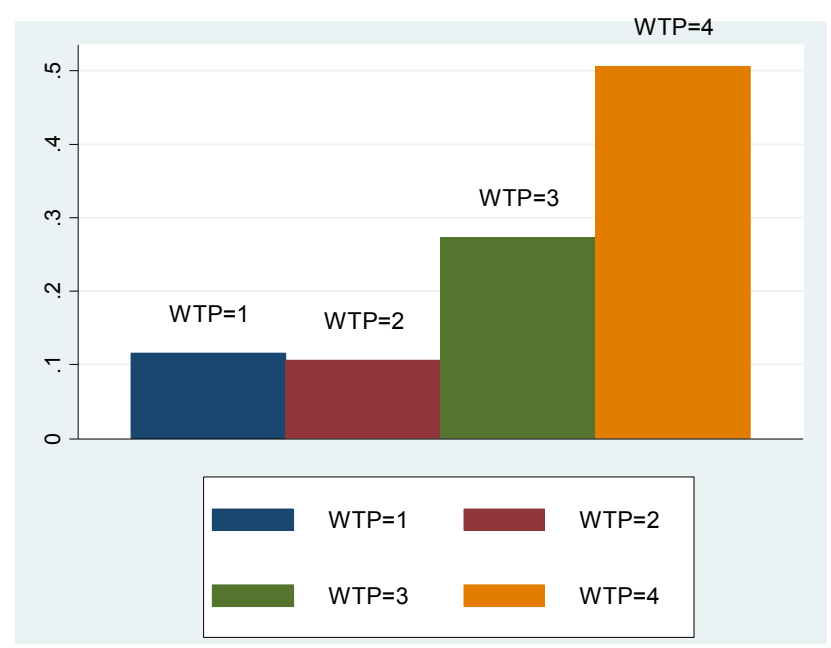

Figure 1. Predicted Probabilities for the four WTP Categories.

However, these probabilities are not very informative. What is more informative are the marginal effects discussed in Section 3.2.

\subsection{Estimated Marginal Effects}

Marginal effects show the change in the predicted probability for each WTP category for an avarge respondent given a unit increase in an explanatory variable. In the case of a categorical variable, the marginal effect is the change in the predicted probability given that a respondent falls into a category of the variable. Results of Table 3 show that being in the age- group 18-30 increased the probability of falling in the high WTP and moderate WTP categories by $40.34 \%$ and $2.76 \%$ respectively, but decreased the probability of being in the low WTP, and no WTP categories by $7.85 \%$, and $35.25 \%$ respectively. This implies that clients in this age group are more likely to be in the high WTP category than those in the reference category.

Also, being in the age-group 31-45 years increased the probability of falling in the high WTP and moderate WTP categories by $44.55 \%$ and $1.29 \%$ respectively, but decreased the probability of being in the low WTP, and no WTP categories by $8.95 \%$, and $36.89 \%$ respectively.

The marginal effects are negative for unemployed, civil servants and self-employed for high WTP, but positive for other categories of WTP. This implies unemployed respondents are $26.37 \%$ less likely to be in the high WTP category, but more likely to be in moderate, low and no WTP categories by $7.45 \%, 6.73 \%$, and $12.19 \%$ respectively.

The marginal effects of all the income categories are positive for high WTP, but negative for the other WTP categories. This suggests respondents who are in GHC 100 GHC 599 income level are $11.95 \%$ more likely to fall in the 
high WTP category, but less likely to be in the moderate WTP, low WTP and no WTP categories by $1.9 \%, 3.18 \%$ and
$6.87 \%$ respectively. Further results of marginal effects are shown in Table 3.

Table 3. Marginal Effects of the ML Estimates.

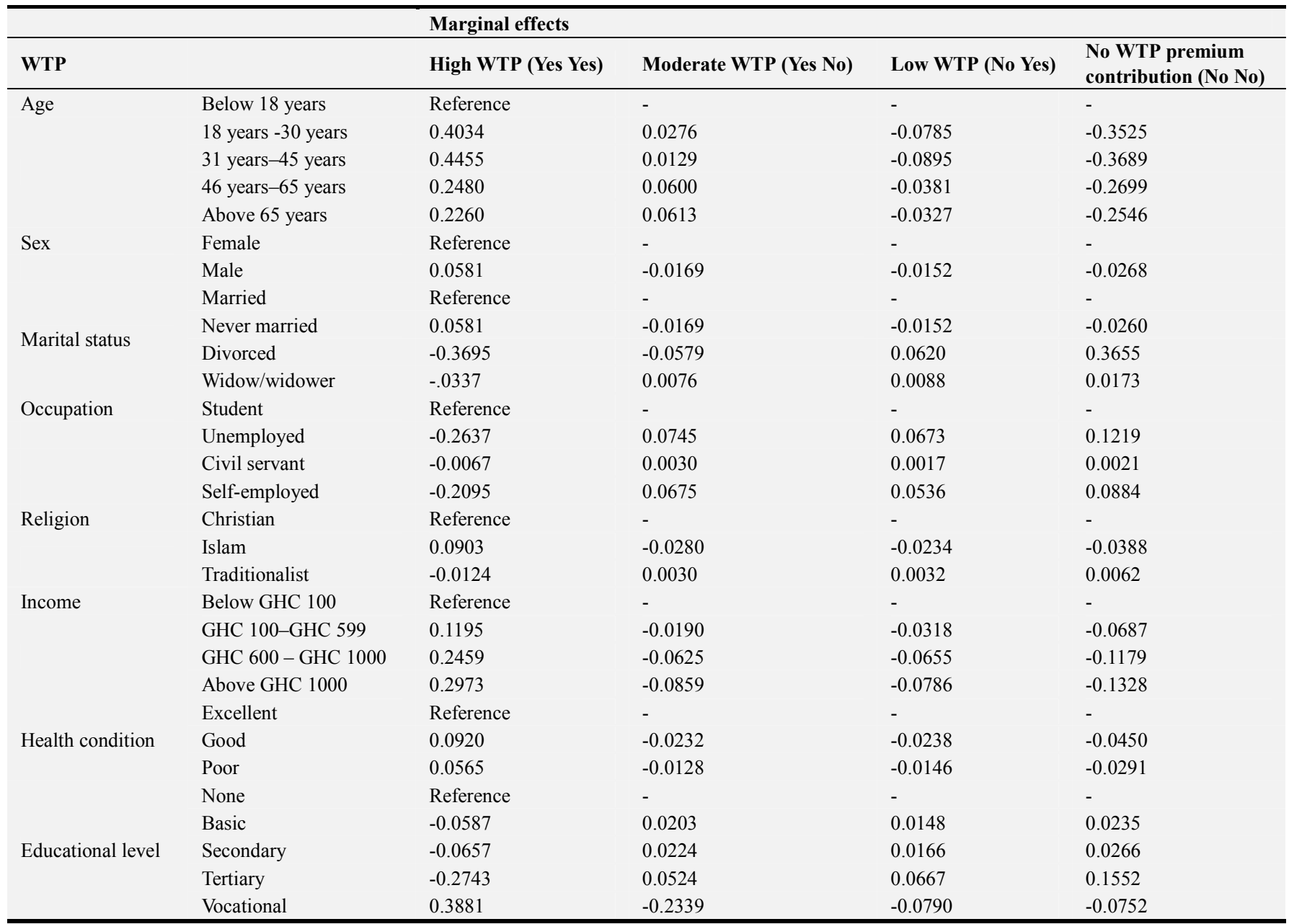

\section{Conclusion}

The main objective of this research was to assess NHIS subscribers' willingness to pay higher premiums for possible improvements in service delivery in the scheme.

Results obtained showed that NHIS users in the Upper East Region of Ghana are enthusiastic of improvement since $86.87 \%$ were WTP more for those improved conditions. Generally clients in the region have high willingness to pay for a better NHIS.

Furthermore, results showed that age-groups 18-30, 30-45, unemployed, tertiary education and higher levels of income significantly influenced WTP.

Prediction results showed that for any average national health insurance user, the probability of being in high WTP, moderate WTP, low WTP and no WTP respectively are 0.51 , $0.27,0.11$ and 0.12 .

Based on the results of this study, stakeholders should consider the possible improvements in the national health insurance scheme (NHIS).

Premiums should be variable across the population in order to meet the different needs of clients. This could also fill the funding gap between high costs of healthcare and the diminishing funding pool.

\section{References}

[1] I. Adisah-Atta (2017). Financing Health Care in Ghana: Are Ghanaians Willing to Pay Higher Taxes for Better Health Care? Findings from Afrobarometer, Social sciences, 6 (3): 1-19.

[2] P. Alagidede, W. Baah-Boateng, E. Nketiah-Amponsah (2013). The Ghanaian Economy: An Overview, Ghanaian Journal of Economics, 1: 1-33.

[3] J. Okoroh, S. Essoun, A. Seddoh, H. Harris, J. S. Weissman, L. Dsane-Selby, R. Riviello (2018). Evaluating the impact of the national health insurance scheme of Ghana on out of pocket expenditures: a systematic review, BMC Health Serv. Res. 18: $1-35$.

[4] Ahmed S., Hoque M. E., Sarker A. R., Sultana M., Islam Z., Gazi R., Jahangir A. M. (2016). Willingness-to-Pay for Community-Based Health Insurance among Informal Workers in Urban Bangladesh, 11 (2): 148-211. 
[5] Tundui, C., \& Macha, R. (2014). Social Capital and Willingness to Pay for Community BasedHealth Insurance: Empirical Evidence from Rural Tanzania; Journal of Finance and Economics, 2 (4): 50-67.

[6] Bolyle K. J. (2003). Contingent Valuation in Practice. In Champ, P. A., K. J. Boyle, and T. C. Brown, eds. A Primer on Nonmarket Valuation. Dordrecht, The Netherlands: Kluwer Academic Publishers: 111-158.

[7] Carson R., Flores N. (2000). Contingent valuation: controversies and evidence, Environmental and Resource Economics, 19 (2): 173-210.

[8] Agresti, A. (2019). An Introduction to Categorical Data Analysis. USA. John Wiley and Sons, Inc.,: 159-187.

[9] D. Bonato, S. Nocera, H. Telser (2001). The Contingent Valuation Method in Health Care: An Economic Evaluation of Alzheimer's Disease, Switzerland, Universität Bern.
[10] Brant, R. (1990). Assessing proportionality in the proportional odds model for ordinal logistic regression. Biometric, 46: 1171-1178.

[11] Puurbalanta, R., \& Adebanji, A. O. (2016). Household Poverty-Risk Analysis and Prediction Using Bayesian Ordinal Probit Models. International Journal of Statistics and Applications, 6 (6): 399-407.

[12] Greene W. H., Hensher D. A. (2009). Modeling Ordered Choices, New York University, New York: 88-95.

[13] Clogg C., Shihadeh E. S. (1994). Statistical models for ordinal variables. Thousand Oaks, California.

[14] Gelfand, A. E., Smith A. F. M. (1990). Sampling-Based Approaches to Calculating Marginal Densities, Journal of the American Statistical Association, 85 (410): 398-409

[15] StataCorp. (2015). Stata Statistical Software: Release 14. College Station, TX: StataCorp LP. 